\title{
The role of PGE2 and PGF2 $\alpha$ in follicle wall rupture and their implications in the development and treatment of luteinized unruptured follicles
}

\author{
Juan Cuervo-Arango and Rebeca Martínez-Boví \\ Departamento de Medicina y Cirugía Animal, Facultad de Veterinaria, Universidad CEU Cardenal Herrera, Alfara del Patriarca, Spain
}

\begin{abstract}
Summary: The article summarizes the results of several studies, which highlight the relevance of prostaglandins E2 (PGE2) and F2 (PGF2 $\alpha$ ) during the ovulatory process in mares and their implication in the pathogenesis of luteinized unruptured follicles. Following the preovulatory luteinizing hormone (LH) surge, the two prostaglandins are synthesized in granulosa cells. They subsequently trigger a cascade of events that lead to ovulation. The exogenous administration of intrafollicular PGE2 and PGF2 $\alpha$ can induce follicle rupture and ovulation within $12 \mathrm{~h}$ of injection, even in mares in early estrus, and before the beginning of the abrupt rise of the preovulatory LH surge. The systemic administration of a prostaglandin synthesis inhibitor (flunixin-meglumine) during the periovulatory period blocks ovulation and induces the development of luteinized unruptured follicles (LUFs). LUFs share similar ultrasonographic and hormonal characteristics with hemorragic anovulatory follicles (HAFs). The administration of intrafollicular PGE2 and PGF2 $\alpha$ in mares treated with a prostaglandin synthesis inhibitor restores normal ovulation and allows oocyte release and fertilization. However, the systemic administration of prostaglandins does not appear to have any effect on hastening ovulation.
\end{abstract}

Keywords: mare / reproduction /ovulation / LUF / PGE2 / PGF2 $\alpha$

Citation: Cuervo-Arango J., Martínez-Boví R. (2016) The role of PGE2 and PGF2 $\alpha$ in follicle wall rupture and their implications in the development and treatment of luteinized unruptured follicles. Pferdeheilkunde 32, 54-56

Correspondence: Dr. Juan Cuervo-Arango, Departamento de Medicina y Cirugía Animal, Facultad de Veterinaria, Universidad CEU Cardenal Herrera, Alfara del Patriarca 46115,Spain; E-mail: juan.cuervo@uch.ceu.es

\section{Introduction}

The inducible isoform prostaglandin G/H synthase 2 (PGHS2) begins to be expressed in granulosa cells about $10 \mathrm{~h}$ before ovulation in several domestic species (Sirois and Dore 1997). In the mare, this timing corresponds with 26 to $30 \mathrm{~h}$ after the beginning of the preovulatory luteinizing hormone (LH) surge (Sirois and Dore 1997). The enzyme PGHS-2 has a cyclooxygenase activity responsible for the production of prostaglandin $\mathrm{H} 2$ (PGH2), the precursor of all prostaglandins. The follicular fluid of the preovulatory dominant follicle shows increasing amounts of prostaglandins E2 (PGE2) and F2 (PGF2) beginning $33 \mathrm{~h}$ after hCG treatment, and reaching peak concentrations of 40 and $10 \mathrm{ng} / \mathrm{mL}$, respectively, $36 \mathrm{~h}$ after human chorionic gonadotropin ( $\mathrm{hCG}$; Sirois and Dore 1997). The endogenous preovulatory LH surge and resultant induction of PGHS-2 expression (Sirois and Dore 1997) can be induced by exogenous treatment of hCG in the mare (Ginther et al. 2009a).

\section{The obligatory role of PGE2 and PGF2 $\alpha$ in the process of ovulation}

Prostaglandins E2 and F2 are essential key factors during the ovulatory process. Its obligatory role in ovulation has been proven by several studies in which their synthesizing enzyme (PGHS-2) was inhibited by systemic treatment with flunixinmeglumine (FM), a non-steroidal anti-inflammatory drug (Cuervo-Arango and Domingo-Ortiz 2011; Cuervo-Arango et al. 2011; Cuervo-Arango 2011). The majority of mares treated intravenously with FM during the periovulatory period did not ovulate but developed a luteinized unruptured follicle
(LUF; Cuervo-Arango et al. 2011). The ultrasound morphology of the FM-induced LUF is similar to that reported in mares with naturally occurring haemorrhagic anovulatory follicles (HAF; Cuervo-Arango and Newcombe 2012). The first evidence of LUF development (presence of echoic specks floating freely within the follicular antrum) is observed $44 \mathrm{~h}$ after hCG treatment (Cuervo-Arango et al. 2011).

On the other hand, the timing of FM treatment related to hCG administration appears to be important for the outcome of ovulation or LUF formation. When FM $(1.7 \mathrm{mg} / \mathrm{kg})$ is administered every $12 \mathrm{~h}$ beginning at the time of (Hour 0 ), or $24 \mathrm{~h}$ after hCG treatment, the incidence of LUF is $83 \%$ and $80 \%$, respectively (Cuervo-Arango 2011). However, if FM is administered only once, either 24 or $30 \mathrm{~h}$ after hCG, $100 \%$ of mares ovulate normally. Finally, mares treated with FM twice at 28 and $36 \mathrm{~h}$ after hCG, have a LUF incidence of $16.7 \%$ (Cuervo-Arango 2011). Thus, it can be concluded that in order to block ovulation, PGHS-2 function must be inhibited during the critical time window between 24 and $36 \mathrm{~h}$ after hCG treatment.

\section{Are PGE2 and PGF2 $\alpha$ able to induce ovulation before the LH surge?}

The latter series of studies showed the obligatory role of prostaglandins during the process of follicle wall rupture and ovulation. However, the prostaglandin-dependent mediators of the follicular extracellular matrix degradation required for ovulation are unknown. Studies in other species (cattle) have shown that prostaglandins activate extracellular matrix degrading 
enzymes such as the MMP (matrix-metalloproteinase) family and plasmin (Li et al. 2006). On the other hand, it is likely that many other factors are involved in the process of ovulation, oocyte maturation, and release, all of them orchestrated by the action of gonadotropins (Robker et al. 2000). A recent experiment (Martínez-Boví et al. 2015) tested the hypothesis of whether the intrafollicular administration of PGE2 and PGF2 $\alpha$ in a 4:1 ratio (similar to that observed during the physiological process of ovulation) would induce ovulation in mares in early estrus (before the beginning of the abrupt rise of the preovulatory LH surge). In this study, 6 mares were treated during 2 consecutive cycles with either a placebo $(0.5 \mathrm{~mL}$ of water for injection) or a solution of $0.5 \mathrm{~mL}$ containing $500 \mu \mathrm{g}$ of PGE2 (dinoprostone $10 \mathrm{mg} / \mathrm{mL}$, PGE2-Pfizer; Pfizer España, Alcobendas, Spain) and $125 \mu \mathrm{g}$ of PGF $2 \alpha$ (dinoprost $5 \mathrm{mg} / \mathrm{mL}$, Dinolytic; Pfizer España) by intrafollicular administration into the dominant follicle during early estrus (follicle diameter of 30 to $32 \mathrm{~mm}$ without concurrent treatment with hCG). Mares were inseminated with frozen/ thawed semen immediately before follicle puncture. No mare treated with the placebo ovulated within $24 \mathrm{~h}$ of follicle puncture: the mean interval from treatment to ovulation was $72 \pm 10.7 \mathrm{~h}$. On the other hand, 4 out of 6 mares treated with the prostaglandin solution ovulated within $12 \mathrm{~h}$ of treatment (mean interval to ovulation of $20 \pm 8.9 \mathrm{~h}$ ). It was concluded that the mixed solution containing PGE2 and PGF2 $\alpha$ was able to induce follicle wall rupture and collapse despite being administered early in estrus, apparently before the beginning of the abrupt rise of the preovulatory LH surge. This finding highlights the potency of these prostaglandins to trigger ovulation on their own. Furthermore, this protocol would be potentially applicable to equine reproduction because of the rapid induction of ovulation. However, in treated mares the postovulatory rise in progesterone was delayed about 2 days compared with mares from the placebo group that ovulated spontaneously. In addition, no mare became pregnant. Whether these unsuccessful inseminations were due to a lack of oocyte maturation because of low LH concentrations, is unknown and requires further study.

\section{Can PGE2 and PGF2 restore normal ovulation in mares treated with a prostaglandin synthesis inhibitor?}

Once it is evident that an intrafollicular administration of PGE2 and PGF2 $\alpha$ on its own can induce follicle wall rupture and ovulation, it is logical to suspect that it could be used as a potential treatment of anovulatory conditions such as HAFs. A recent study partially tested this hypothesis (Martínez-Boví and Cuervo-Arango 2014). Since HAFs are an unpredictable condition, an experimental model involving systemic administration of FM to inhibit PGHS-2 and induce LUF was used. In the reported study, mares were treated with FM every $12 \mathrm{~h}$ from Hour 0 (Hour of hCG administration) during two consecutive cycles to block the synthesis of follicular prostaglandins. Subsequently, mares were either treated with a placebo $(0.5 \mathrm{~mL}$ of water for injection) or a mixed solution of $0.5 \mathrm{~mL}$ containing $500 \mu \mathrm{g}$ PGE2 and $125 \mu \mathrm{g}$ PGF2 $\alpha$, $32 \mathrm{~h}$ after hCG administration. Three mares in each group were inseminated with fresh semen $24 \mathrm{~h}$ after hCG. All mares in the treatment group ovulated within 12 h of PGE2 and PGF2 $\alpha$ administration (5/5), and became pregnant (3/3). However, only one mare $(1 / 5)$ ovulated in the placebo group. The rest $(4 / 5)$ developed a LUF and none become pregnant (0/3).
In this experimental model, the prostaglandin treatment solution was able to overcome the anovulatory effect of FM and induce ovulation and apparent successful release of the oocyte, since all inseminated mares became pregnant. It is worth emphasizing that all mares were treated with hCG to initiate the abrupt rise of the preovulatory $\mathrm{LH}$ surge and therefore ovulation in mares from the treatment group took place between 36 and $48 \mathrm{~h}$ after hCG administration, a time window considered physiological for normal ovulation in hCG-treated mares.

The pathogenesis of naturally occurring HAF remains largely unknown. It is likely that factors other than intrafollicular prostaglandins are involved in the inhibition of ovulation in mares with HAF. However, because of the highly similar morphological and hormonal characteristics between naturally occurring HAF and FM-induced LUF (Cuervo-Arango and Newcombe 2012), as well as the ability of a combination of exogenous PGE2 and PGF2 $\alpha$ to induce ovulation on its own, the potential usefulness of this protocol to prevent the formation of HAF should be studied further.

\section{Systemic treatment with PGE2 and PGF2 $\alpha$ : follicular vs. systemic effects}

It seems logical to research the effect of prostaglandins on restoring ovulation administered by the systemic route. Although the intrafollicular route has been proven to be successful, it is more time consuming and requires specialized equipment (i.e. transvaginal ultrasound probe), which are not always available for the field practitioner.

The challenge of the systemic route approach is to determine the minimum effective dose of PGE2 and PGF2 $\alpha$ capable of reaching the granulosa and theca layers to induce ovulation with the minimal adverse side effects. Prostaglandin E2 is used in human reproductive medicine for its ecbolic and cervical relaxation properties. The main indication of PGE2 is induction of labor administered as a vaginal pessary (Mozurkewich et al. 2011 ). The use of PGE2 by the intravenous route to induce labor was attempted in the past but now it has been discontinued in favor of the vaginal route because of increased adverse side effects such as gastrointestinal symptoms and fever (reviewed by Mozurkewich et al. 2011). The indications stated in the data sheet of the human product (PGE2-Pfizer $10 \mathrm{mg} / \mathrm{mL}$ intravenous infusion; Pfizer España) used for the previous experiments in mares, are molar pregnancy and induction of late term abortion. The manufacturer recommends the use of diluted PGE2 $(5 \mu \mathrm{g} / \mathrm{mL})$ by intravenous infusion at a starting rate of $2.5 \mu \mathrm{g} / \mathrm{min}$ and no more than $10 \mu \mathrm{g} / \mathrm{min}$. Possible adverse side effects such as nausea, vomiting, diarrhea, dizziness, trembling, hypertension, and heart attack, etc., are described.

Data on the use of PGE2 in mares are scarce and have been limited to local therapy in the follicle (Martínez-Bovi and Cuervo-Arango 2014), oviduct (Weber et al. 1991, Allen et al. 2006), uterus (Weber et al. 1991), and cervix (Rigby et al. 1998). To the author's best knowledge, only one published study has reported the intramuscular treatment of $10 \mathrm{mg}$ of PGE2 in six mares as a single bolus (Weber et al. 1991). However, no mention of side effects following the systemic administration of PGE2 was made. The objective of the latter 
study was to accelerate oviductal embryo descent. Only the intraoviductal infusion of PGE2, but not the intramuscular treatment caused a positive effect and hastened the embryo's oviductal transit in some mares.

The use of systemic (intramuscular or subcutaneous) treatment of PGF2 (dinoprost) or one of its synthetic analogues is common practice in equine reproductive medicine. Following intramuscular administration of the manufacturer's recommended dose of PGF2 $\alpha(5 \mathrm{mg})$, slight adverse side effects can be observed in some mares (about 10\%), such as sweating, diarrhea, or colic (Irvine 1993). However, when cloprostenol was administered intravenously $(250 \mu \mathrm{g}$, manufacturer's recommended dose), severe adverse side effects such as ataxia and profuse diarrhea as well as sweating were noted in 100\% of treated mares (Cuervo-Arango 2011).

In a preliminary study, (originally reported herein), two mares were treated with $10 \mathrm{mg}$ of PGE2 and $2.5 \mathrm{mg}$ of PGF2 $\alpha$ either as a single intravenous or intramuscular bolus when they were in estrus with a follicle of $35 \mathrm{~mm}$ in diameter. The mares were scanned every $12 \mathrm{~h}$ until ovulation. Within 2 minutes of treatment, the intravenously treated mare showed profuse sweating and drooling, ataxia, weakness of the hind limbs, abdominal discomfort, and increased intestinal peristaltism. Signs of colic lasted for $12 \mathrm{~h}$. The interval to ovulation in this mare was $84 \mathrm{~h}$. The mare treated intramuscularly showed no adverse side effects other than a slight rise in heart rate. The interval to ovulation was $72 \mathrm{~h}$. It seems that $10 \mathrm{mg}$ of PGE2 administered as a single systemic bolus did not affect the hastening of ovulation.

In a subsequent series of experiments (originally reported herein), the same amount of PGE2 $(10 \mathrm{mg})$ and PGF2 $\alpha(2.5 \mathrm{mg})$ were diluted in $250 \mathrm{~mL}$ of saline and administered to mares in estrus with a follicle of $32-35 \mathrm{~mm}$ in diameter, $24 \mathrm{~h}$ after hCG treatment, by constant intravenous infusion either throughout $2 \mathrm{~h}(\mathrm{n}=5)$ or $4 \mathrm{~h}(\mathrm{n}=4)$. In addition, mares were treated with FM at 24 and $36 \mathrm{~h}$ after hCG, to ensure that ovulation would be blocked. Overall, 7/9 mares failed to ovulate but developed a LUF. One mare from each group ovulated between 60 and $72 \mathrm{~h}$ after hCG. The adverse side effects were mild: no mare showed sweating, diarrhea, or ataxia. Most of the mares showed some sort of abdominal discomfort and adopted a urinating position with straining every 10 to $15 \mathrm{~min}$ throughout the duration of the infusion.

These preliminary results were disappointing. Although the protocol chosen for systemic administration of prostaglandins appeared to be bearable for the mares, it did not have a positive effect upon follicle rupture and ovulation. A similar approach, but designed to induce full luteolysis, achieved a positive luteolytic result following intravenous administration of a low dose of PGF2 $\alpha(0.1 \mathrm{mg})$ diluted in saline and infused at a constant rate over a period of $2 \mathrm{~h}$ (Ginther et al. 2009b). Needless to say, perfusion of the CL and the follicle and the resultant arrival of prostaglandin at its target receptors within the ovary may be completely different in these two ovarian structures.

\section{Conflict of interest statement}

The authors have no conflict of interest to declare.

\section{Animal Welfare statement}

All animal procedures reported in this manuscript have been approved by the local welfare committee of the Universidad CEU Cardenal Herrera (ref: PRCEU-UCH 13/14).

\section{Acknowledgments}

This study was funded by the Universidad CEU Cardenal Herrera, project number FUSP-BS-PPC-01-2014 and by the Generalitat Valenciana, project number GV-2014-129.

\section{References}

Allen W. R., Wilsher S., Morris L., Crowhurst J. S., Hillyer M. H., Neal H. N. (2006) Laparoscopic application of PGE2 to re-establish oviducal patency and fertility in infertile mares: a preliminary study. Equine Vet. J. 38, 454-459

Cuervo-Arango J. (2011) The effect of treatment with flunixin meglumine at different times relative to hCG administration on ovulation failure and luteal function in mares. Anim. Reprod. Sci. 127, 84-90

Cuervo-Arango J., Domingo-Ortiz R. (2011) Systemic treatment with high dose of flunixin-meglumine is able to block ovulation in mares by inducing hemorrhage and luteinisation of follicles. Theriogenology 75, 707-714

Cuervo-Arango J., Beg M. A., Ginther O. J. (2011) Follicle and systemic hormone interrelationships during induction of luteinized unruptured follicles with a prostaglandin inhibitor in mares. Theriogenology 76, 361-373

Cuervo-Arango J., Newcombe J. R. (2012) Ultrasound characteristics of experimentally induced luteinized unruptured follicles (LUF) and naturally occurring hemorrhagic anovulatory follicles (HAF) in the mare. Theriogenology 77, 514-524

Ginther O. J., Beg, M. A., Gastal E. L., Gastal M. O., Cooper D. A. (2009a) Treatment with human chorionic gonadotropin (hCG) for ovulation induction is associated with an immediate $17 \beta$-decrease and a more rapid LH increase in mares. Anim. Reprod. Sci. 114, $311-317$

Ginther O. J., Siddiqui M. A., Beg M. A. (2009b) Physiologic and nonphysiologic effects of exogenous prostaglandin F2alpha on reproductive hormones in mares. Theriogenology 72, 417-424

Irvine C. H. G. (1993) Equine Reproduction, pp. 319-324. Eds: A. $\bigcirc$ McKinnon and J. L Voss, Lea and Febiger, Philadelphia

Martínez-Boví R., Cuervo-Arango J. (2014) Intrafollicular treatment with prostaglandins PGE2 and PGF2 $\alpha$ inhibits the formation of luteinised unruptured follicles and restores normal ovulation in mares treated with flunixin-meglumine. Equine Vet. J. In Press, doi: 10.1111/evj.12396

Martínez-Boví R., Domingo-Ortiz R., Cuervo-Arango J. (2015) Intrafollicular treatment with prostaglandins E2 and F2 $\alpha$ induces ovulation in mares in early oestrus. Submitted to Theriogenology.

Mozurkewich E. L., Chilimigras J. L., Berman D. R., Perni U.C., Romero V. C., King V. J., Keeton K. L. (2011) Methods of induction of labour: a systematic review. BMC Pregnancy Childbirth 11, 84

Li Q, Jimenez-Krassel F., Kobayashi Y., Ireland J. J., Smith G. W. (2006) Effect of intrafollicular indomethacin injection on gonadotropin surge-induced expression of select extracellular matrix degrading enzymes and their inhibitors in bovine preovulatory follicles. Reproduction 131, 533-544

Rigby S., Love C., Carpenter K., Varner D., Blanchard T. (1998) Use of prostaglandin E2 to ripen the cervix of the mare prior to induction of parturition. Theriogenology 50, 897-904

Robker R. L., Russell D. L., Yoshioka S., Sharma S. C., Lydon J. P., O'Malley B. W., Richards J. S. (2000) Ovulation: a multi-gene, multi-step process. Steroids 65, 559-570

Sirois J., Dore M. (1997) The late induction of prostaglandin G/H synthase-2 in equine preovulatory follicles supports its role as a determinant of the ovulatory process. Endocrinol.138, 4427-4434

Weber J. A., Freeman D. A., Vanderwall D. K., Woods G. L. (1991) Prostaglandin E2 hastens oviductal transport of equine embryos. Biol. Reprod. 45, 544-546 